\title{
On the use of the Radon transform to estimate longshore currents from video imagery
}

\section{Stanislas Larnier, Rafael Almar, Rodrigo Cienfuegos, Antoine Lejay}

\begin{abstract}
In nearshore applications, the estimation of longshore currents is of primary importance since it controls the alongshore sediment transport and coastal evolution. Direct estimation of longshore currents using in-situ instruments is difficult and costly, especially under highly energetic wave climates. Low cost remote sensing systems based on video observations constitute a promising alternative when the drifting sea foam left after the passage of breaking waves is visible. In this paper we describe a method based on longshore timestacks that necessitates less data than approaches using the full video frames. Our approach uses the Radon transform applied on the time series derived from timestacks to produce an estimate of the longshore component of nearshore surface currents detected from the foam signature in video images. The Radon transform can be used to separate the wave crests from the drifting foam part. The identification of the longshore drift is enhanced with both a temporal and a spatial filters. The corresponding sinogram from the Radon transform is computed in order to find the angle of the alongshore drifting that is further converted into the longshore component of the surface currents. For the estimation of longshore currents, our approach is first tested using synthetic timestack examples created using anisotropic Gaussian random current fields. Comparisons between estimates derived by our algorithm and manual operator detection from videos are performed showing good agreement. These videos come from a field campaign conducted in the Mataquito River mouth area in the Maule region (Chile). Field test comparisons were also made against in situ current meter from the 2008 Truc Vert experiment in Aquitaine (France). It was taking place during an energetic event.
\end{abstract}

\section{INTRODUCTION}

Wave energy is generated by converting the energy of ocean waves, swells, into other forms of electricity energy. Wave energy provides 15 to 20 times more available energy per square meter than either wind or solar and is also more regular (Muetze and Vining, 2006). With a long coastline where the Pacific Ocean is highly energetic, Chile, country partner of the project, plans to invest in this renewable energy.

The multi-disciplinary Franco-Chilean project behind this study intends to use low cost remote sensing systems based on video observations to determine the energy potential of a site. For this, we need to estimate the average period, average speed, and average wave height, average speed of coastal currents, the angle between incoming wave front and the coast, and bathymetry.

Remote sensing systems have been developed for over twenty years. They were used to detect morphology of submerged sandbars (Lippmann and Holman, 1990), period and direction of breaking waves (Lippmann and Holman, 1991), the timevarying location of the shore line (Plant and Holman, 1997) and nearshore bathymetry (Stockdon and Holman, 2000). Compared to the use of radar or sensors, this technique has the advantage of having a low cost of installation and use (Almar, 2009). In order to determine correctly geophysical variables, it is necessary to be able to transform the coordinates of

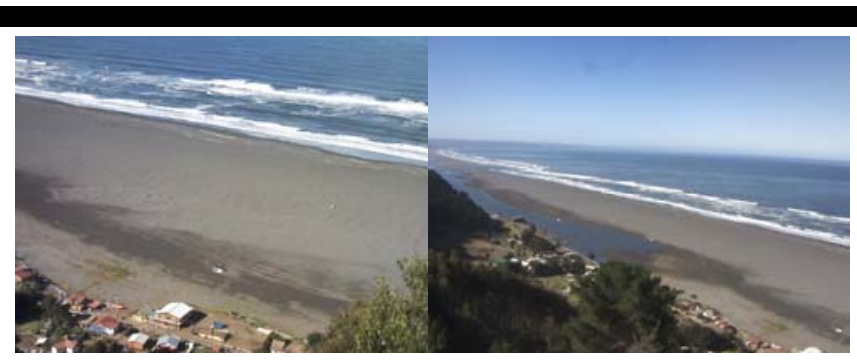

Figure 1. Snapshots from Mataquito cameras, Chile.
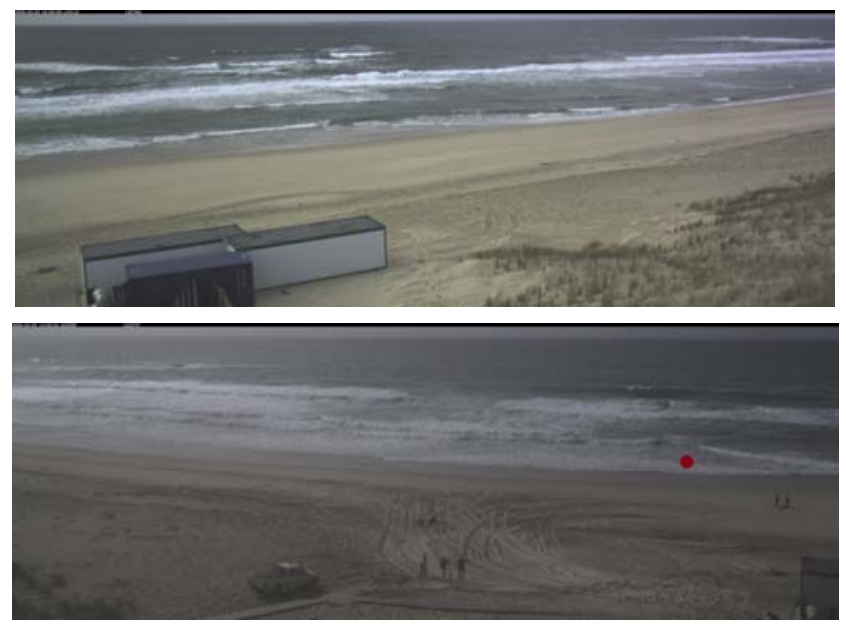

Figure 2. Snapshots from Truc Vert cameras, France.

the image in actual coordinates. Such a transformation is determined from a set of visible ground control points with known geophysical locations (Holman and al., 1993). 
In this article, we are interested only in estimating the average velocity $\mathrm{V}$ of coastal currents using the moving mass of foam created when a wave breaks. The trajectories of the foam are dependent of current and waves.

Methods consider only the current component parallel to the coast (Chickadel, 2003). Others use the whole video as Particle Image Velocimetry (PIV) (Holland et al., 2001).

The videos used in this study come from two field campaigns. The ones from Chile were conducted in the Mataquito River mouth area in Maule region. These videos are part of a study on the post-tsunami coastal recovery of the Mataquito area after 2010 Chilean Tsunami (Villagran et al., 2013). Unlike conventional installation of other campaigns, where the cameras are on a mast near the beach, the system is at the top of a hill in the coastal mountain range. Figure 1 presents two snapshots.

Field test comparisons were also made against in situ current meter from the 2008 Truc Vert experiment in Aquitaine (France). Figure 2 presents two snapshots. In the second one, a red dot marks the current meter location. This study was part of the ECORS program. It took place during an energetic event where rapid sandbar evolution was observed (Senechal et al., 2011).

In section Timestacks, the definition of timestack is recalled then we present a simple approach to obtain synthetic data based on anisotropic Gaussian random fields. The section Radon transform and algorithm presents shortly the Radon transform, main tool of our approach, and the algorithm steps are given and illustrated with a real timestack from Truc Vert experiment. In section Numerical results, our approach is first tested using synthetic timestack examples, then comparisons between estimates derived by our algorithm and a manual operator detection from videos are performed showing good agreement and to conclude a field test comparisons is made against in situ current meter from the Truc Vert experiment.

\section{TIMESTACKS}

\section{True timestacks}

Timestacks are images created from a temporal sequence of selected pixels. Every horizontal line represents a line through the field of the camera to capture a given instant, as the red line, parallel to the coast, in Figure 3. Each vertical line shows the time evolution a fixed point on the line.

Figure 4 shows the resulting corresponding timestack about four periods of the wave front from the red line shown in Figure 3. Wave fronts give the white horizontal lines. The drift of persistent sea foam form oblique lines. The celerity of the surface currents can be estimated from the orientations of these lines. On this picture, the timestack was enlarged from temporal point of view to get a better understanding of the phenomena.

\section{Synthetic timestacks}

It is possible to simulate synthetic longshore timestacks (Chickadel et al., 2003). The approach proposed in this article is based on anisotropic Gaussian random fields.

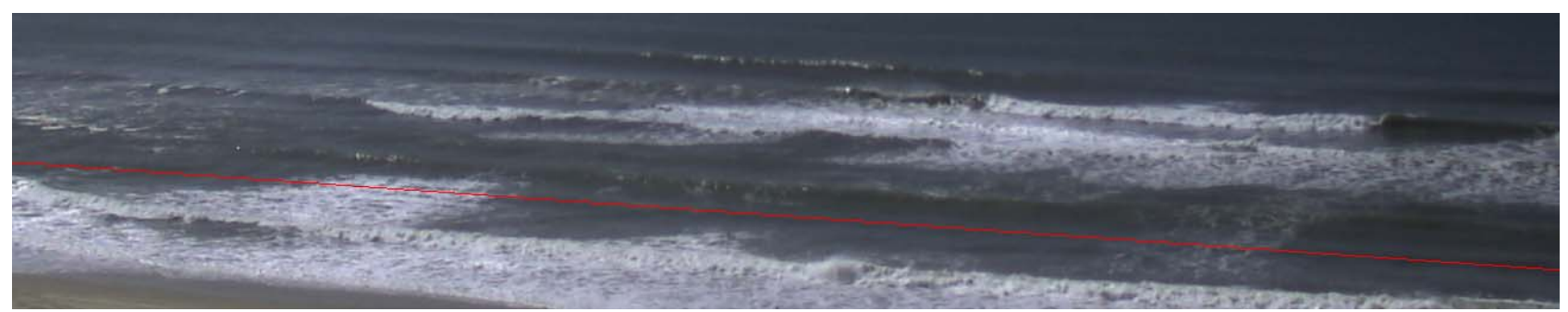

Figure 3. View from Truc Vert site. The red line is the timestack position. The timestack is parallel to the wave front.

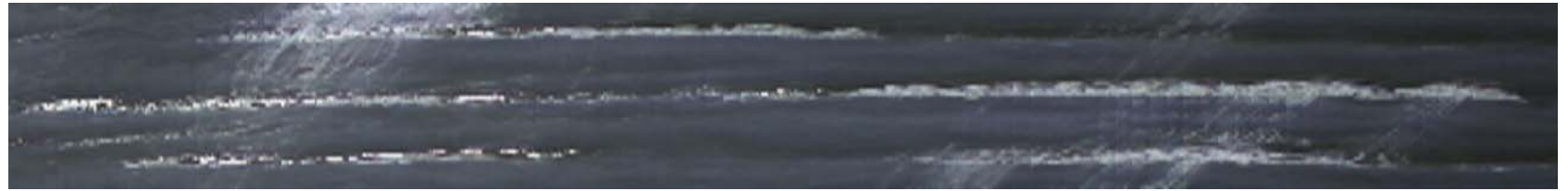

Figure 4. Associated timestack. The horizontal lines are wave crests. The orientation of the other lines created by the foam give the currents celerity along the shore. 

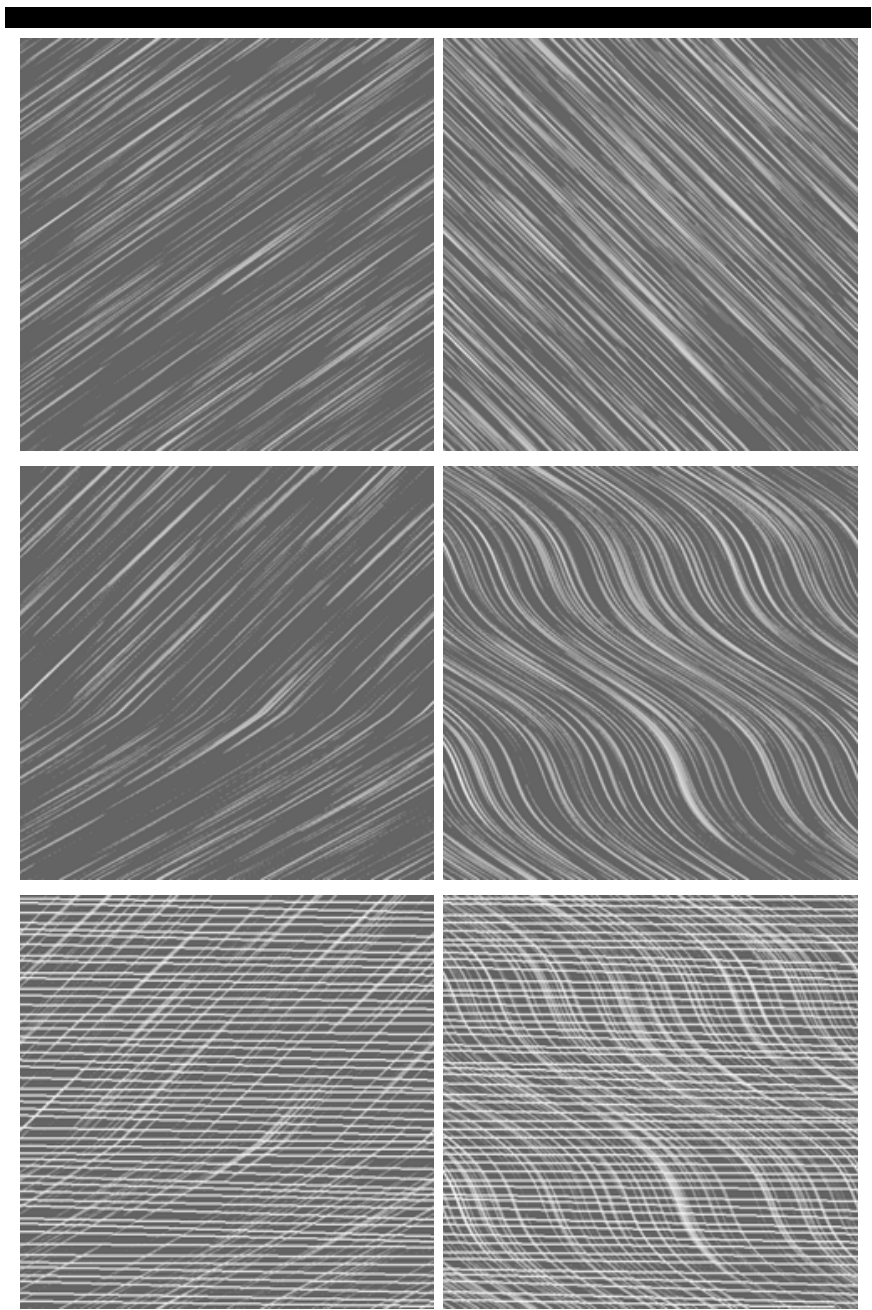

Figure 5. Creation of synthetic longshore timestacks. From up to down, anisotropic random Gaussian fields, deformations of the fields, same images where random wave crests have been added.

The generation algorithm is:

1. Creation of an anisotropic Gaussian random field with an orientation $\theta$;

2. Deformation of the field;

3. Creation of random wave front with a mean period of $\mathrm{T}$;

4. Assemblage of the two.
Figure 5 presents two results from this algorithm. At the top, there are two anisotropic random Gaussian fields with an orientation $\theta=55^{\circ}$ at left and $\theta=135^{\circ}$ at right. At the middle, there are modified in order to obtain a sudden acceleration for the left one and a sinusoidal behavior for the right one. At the bottom, the waves crests are added with a mean period of waves $\mathrm{T}=10$ pixels.

\section{RADON TRANSFORM AND ALGORITHM}

\section{Radon transform}

The Radon transform (Ramm and Katsevich, 1996; Mallat, 2009; Feeman, 2010) $\mathrm{R}(\rho, \theta)$ over a bidimensional field $\eta(\mathrm{x}, \mathrm{y})$ can be defined as:

$$
R(\rho, \theta)=\oiint \eta(x, y) \delta(x \cos \theta+y \sin \theta-\rho) \mathrm{d} x \mathrm{~d} y
$$

where $\delta$ is the Dirac delta function, $\theta$ and $\rho$ are respectively the angle and distance from origin of the integration line defined as $\rho=\cos (\theta)+\sin (\theta)$. The origin is the center of the two-dimension field. The Radon transform is defined for all possible values of $\theta$ from [0 to $\left.180^{\circ}\right]$ and $\rho$ from 0 to the diagonal length.

From an image $\eta$, a sinogram, Radon transform data $\mathrm{R}$ depending of $\rho$ and $\theta$, can be obtained, see Figure 7 for an example. It is possible to filter $\eta$ by modifying the values of $\mathrm{R}$ then using the inverse Radon transform.

The Radon transform is especially used in medical image processing, notably in tomography. Recently, the Radon transform has been successfully applied to study nearshore wave dynamics where it allows the separation of incoming waves from reflected ones (Almar et al, 2013).
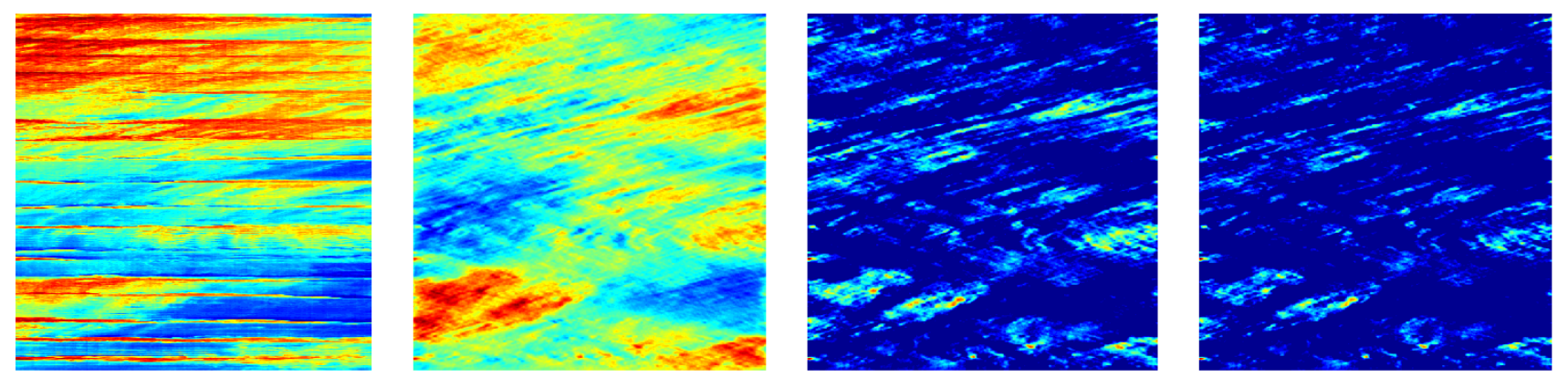

Figure 6. From left to right, original image, image filtered with Radon transform, then with a temporal filter, then with a spatial filter. 


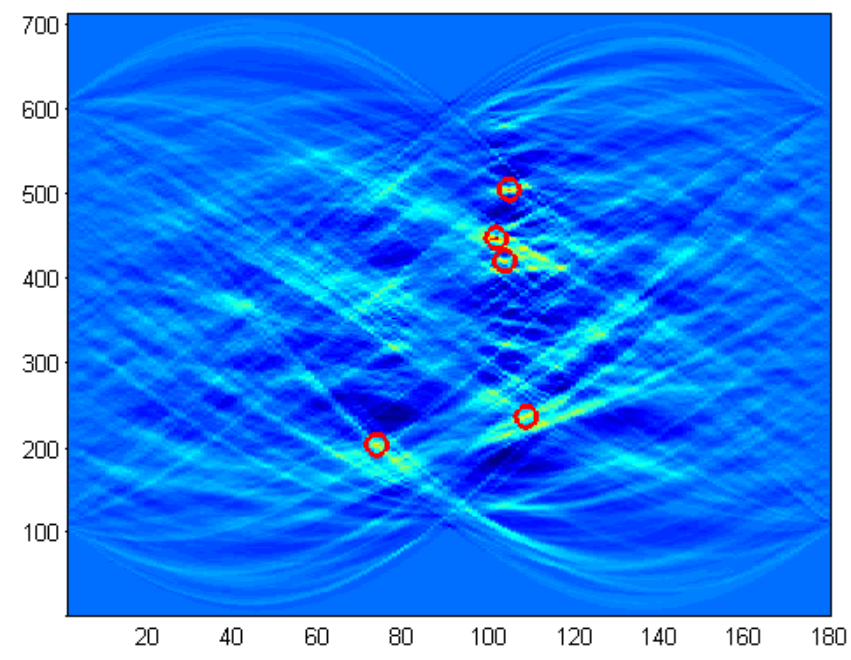

Figure 7. Sinogram (or Radon transform data) of the right image of Fig. 6. Local maxima are in a red circles.

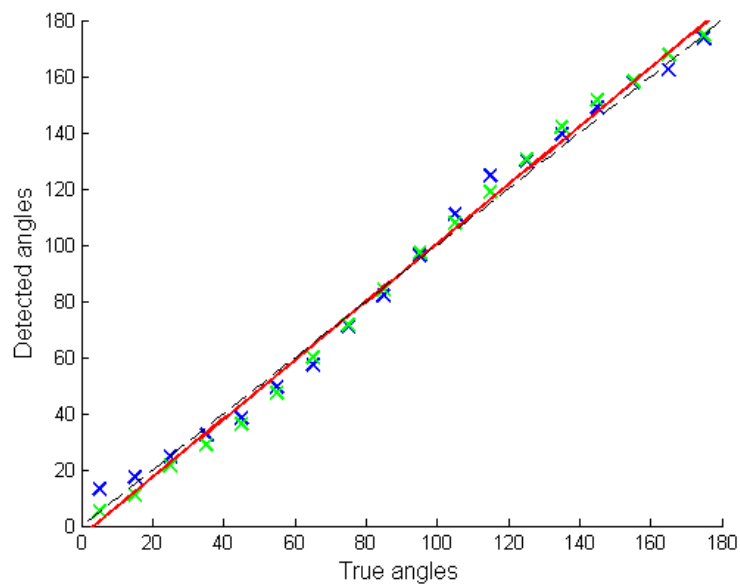

Figure 8. True angles versus detected ones for synthetic data. The blue crosses represent the first type and green crosses the second one, see Figure 5. The linear least squares regression is shown as the thick red line and the dash line is the line $\mathrm{y}=\mathrm{x}$.

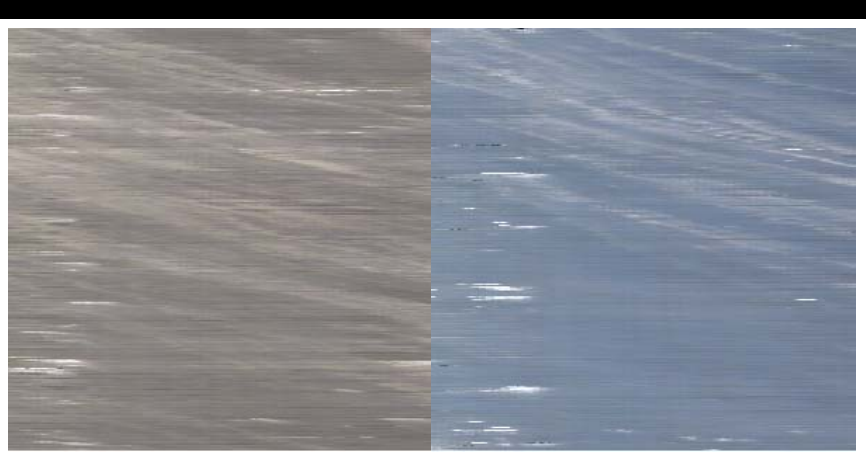

Figure 9. Two timestacks from Mataquito with different illumination conditions.

\section{Orientation detection algorithm}

The algorithm is the following:

1. Use of Radon Transform to delete the horizontal lines (waves) and vertical ones (camera artefacts) with a range of more or less $\mu$,

2. Temporal filter with a high pass filter;

3. Spatial filter in order to keep the high frequency information;

4. Study of Radon coefficients to determine the local maxima;

5. Deletion of extreme values outside of boundary values;

6. Mean of the best ones to obtain the best orientation. In the majority of tests, $\mu$ is equals to $8^{\circ}$. Figures 6 and 7 illustrate the algorithm steps on the 10th of March 2008 from $7 \mathrm{~h} 45$ to $8 \mathrm{~h}$ for Truc Vert campaign. From left to right. Figure 6 presents the timestack and the successive filters applied to the image.

The left image in Figure 6 presents the filtered image in which the orientation of the current will be determined. Even if some zones are not in the correct orientation, the obtained image is usually correct. Radon values for the filtered image are given in the right image of Figure 7 (the original image has been turned a quarter turn) with local maxima above a certain threshold surrounded by a red circle. The sensor has measured an average speed of $-0.64 \mathrm{~m} / \mathrm{s}$ and our algorithm returns $-0.66 \mathrm{~m} / \mathrm{s}$.

\section{NUMERICAL RESULTS}

\section{Tests on synthetic data}

Synthetic stacks were created with an orientation $\theta$ from $5^{\circ}$ to $175^{\circ}$ with a step size of $10^{\circ}$ and with a mean period of waves $\mathrm{T}=10$ pixels. The synthetic image is a square of side 500 pixels and takes its gray values between $[0,255]$. Examples of synthetic stacks are shown in Figure 5.

In these tests, an additive Gaussian noise of standard deviation 50 is added. The correlation between true and detected angles is equals to 0.997 . Figure 8 presents the plot of the true angles versus the detected ones. The blue crosses are the left type of synthetic data in Figure 5; the green crosses are the second one. The red thick line is the linear least square regression and follows the equation $y=1.041 x-3.626$. The black dashed line is a perfect fit.

Note that for angles near a horizontal or a vertical orientation, the angle of deletion is lowered in step 1 of the orientation detection algorithm compared to real images. 


\section{Comparison with human operator}

Figure 9 shows two timestacks taken along the coast on Mataquito site in identical positions but in different light conditions. Manual operator found respectively $13.8^{\circ}$ and $12.6^{\circ}$ for the first and second timestack, against $12.5^{\circ}$ and $13.6^{\circ}$ for the algorithm. The detection algorithm gives results similar to those of a human operator.

Figure 10 presents the plot of manual operator current means versus the algorithm estimations at the Truc Vert during the $10^{\text {th }}$ March 2008, from 12 a.m. to 4 p.m.. The linear least square regression is shown as the red thick line and follows the equation $\mathrm{y}=0.961 \mathrm{x}$ 0.084 . The correlation is equals to 0.81 . The black dashed line is a perfect fit. The worst results are for low velocity, it could come from the climate conditions which make it more difficult for manual operator to estimate the current mean on the studied windows.

\section{Comparison with current meter}

Mean velocity was calculated from the data collected during three days of Truc Vert experiment. This acquisition was made from the $10^{\text {th }}$ to the $12^{\text {th }}$ of March 2008, from 7 a.m. to 6 p.m.. The position of the current meter is represented in Figure 2. It registers at $0.1 \mathrm{~Hz}$, a mean of length $70 \mathrm{~s}$ is performed, and then an interpolation is used to obtain data at the same time than the detection. The detection algorithm gives information at each $240 \mathrm{~s}$ and a mean of length $720 \mathrm{~s}$ is performed.

Figure 12 presents three times series comparisons of mean longshore current estimates from the algorithm (red circles) with the ground thrust data returned from the current meter (blue crosses). Some data are not displayed because they have been taken at low tide and there is not enough water above the current meter to have correct measurements. The worst results are for the positive currents which are near the low tide so they are not completely accurate. The correlation is equals to 0.812 .

Figure 11 shows a more direct comparison between the two estimates. The linear least squares regression follows the equation $y=1.109 x+0.028$ and is the red thick line. The black dashed line is a perfect fit.

\section{CONCLUSION}

This article presents a new approach to estimate longshore currents from video imagery timestacks using the Radon transform. The results on synthetic data, on normal condition or even in the case of an energetic event are promising. It is an alternative to

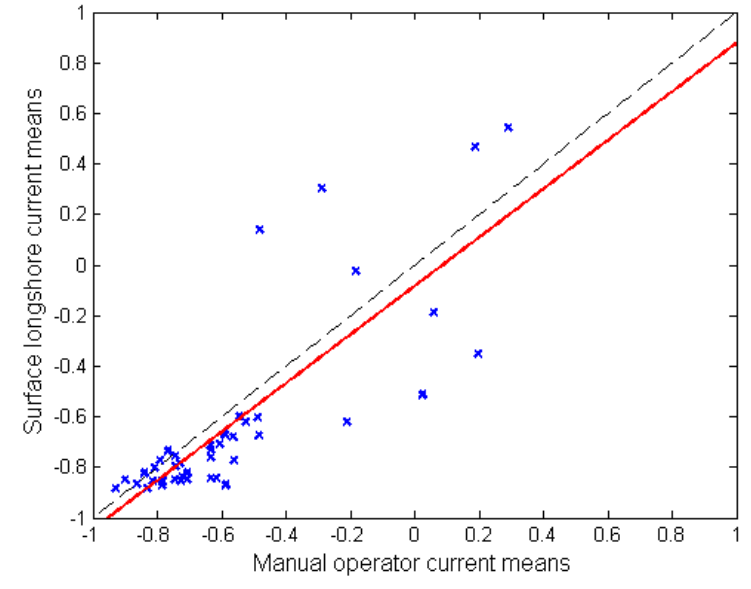

Figure 10. Manual operator current means versus detected ones at the Truc Vert during the $10^{\text {th }}$ March 2008 from 12 p.m. to 4 p.m.. The linear least squares regression is shown as the thick red line and the dash line is the line $\mathrm{y}=\mathrm{x}$.

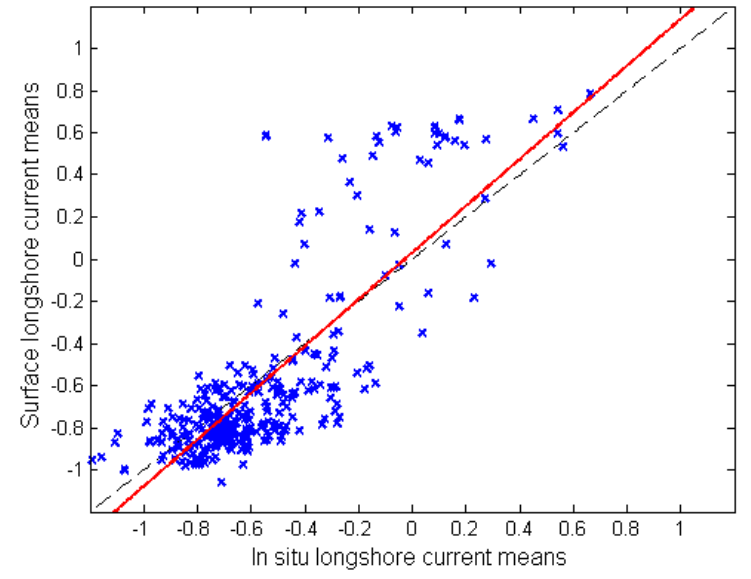

Figure 11. In situ longshore current means versus surface longshore current means. The linear least squares regression is shown as the thick red line and the dash line is the line $y=x$.

other approaches (Chickadel et al., 2003; Holland et al., 2001). Extensive comparative study between these different approaches is under consideration, with also investigation to determine the optimal size windows and some indicators to avoid

poor timestacks due to low contrast or undesirable marks due to for examples birds, boats or humans.

Future research under consideration is a comparison with the investigation of neashore currents from parameters estimated in open sea in Benin (Laibi, R., et al., 2014).

Even if the longshore currents are often the most important part, it could be interesting to have the 

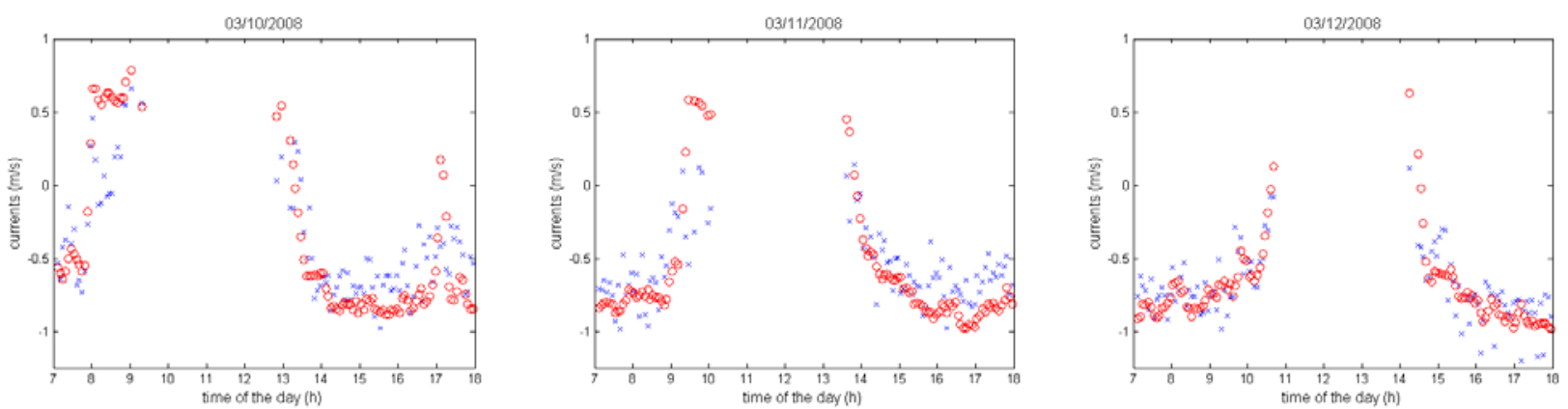

Figure 12. From left to right, optically measured man surface currents (circles) and in situ currents (crosses) for the $10^{\text {th }}$ to the $12^{\text {th }}$ March 2008 at Truc Vert experiment.

global current evolution from video imagery. During our study, we note that Radon transform, can be also used to separate wave crests and foam from a full camera snapshot. Two examples are given in Figure 12. Waves crests orientation is obtained from the sinogram of Radon transform. The separation part is performed like the first step of our estimation algorithm. Particle Image Velocimetry improvement exists (Larnier et al., 2013), and it will be interesting to dig also in this research perspective.

\section{ACKNOWLEDGEMENT}

We acknowledge the Lorraine region, the associated franco-chilean team Anestoc-Inria, and the Centre Inria CIRIC for their financial support. R. Cienfuegos acknowledge partial support from the Fondap program 15110017. The ECORS experiment and Truc Vert video system were supported by the French "Service Hydrographique et Oceanographique de la Marine" $(\mathrm{SHOM})$ and the "Délégation Générale de l'Armement" (DGA). R. Almar funded by the French programs INSU LEFE and EC2CO. R. Cienfuefos and Mataquito video system funded by Chilean project FONDECYT N ${ }^{\circ} 1120878$.

\section{LITERATURE CITED}

Almar, R., 2009. Morphodynamique littorale haute fréquence par imagerie video. $\mathrm{PhD}$ thesis, Université Bordeaux 1, France.

Almar, R., Bonneton, P., Michallet, H. Cienfuegos, R. Ruessink, B.G., and Tissier, M., 2013. On the use of Radon transform in studying nearshore wave dynamics. In Proceedings of Coastal Dynamics, 24-28 June, Arcachon, France, 73-82.

Chickadel, C.C., R.A. Holman, and Freilich, M.H., 2003. An optical technique for the measurement of longshorecurrents. J. Geophys. Research: Oceans, 108(C11).

Feeman, T. G., 2010. The mathematics of medical imaging, A beginner's guide. Springer Undergraduate Texts in Mathematics and Technology. Springer, New York.

Haralick, R.M. and Shapiro, L.G., 1993. Computer and robot vision. Computer and Robot Vision. Addison-Wesley Pub. Co..

Holland, K.T., Puleo, J.A., and Kooney, T.N., 2001. Quantification of swash flows using video-based particle image velocimetry. Coast. Eng., 44(2):65-77.

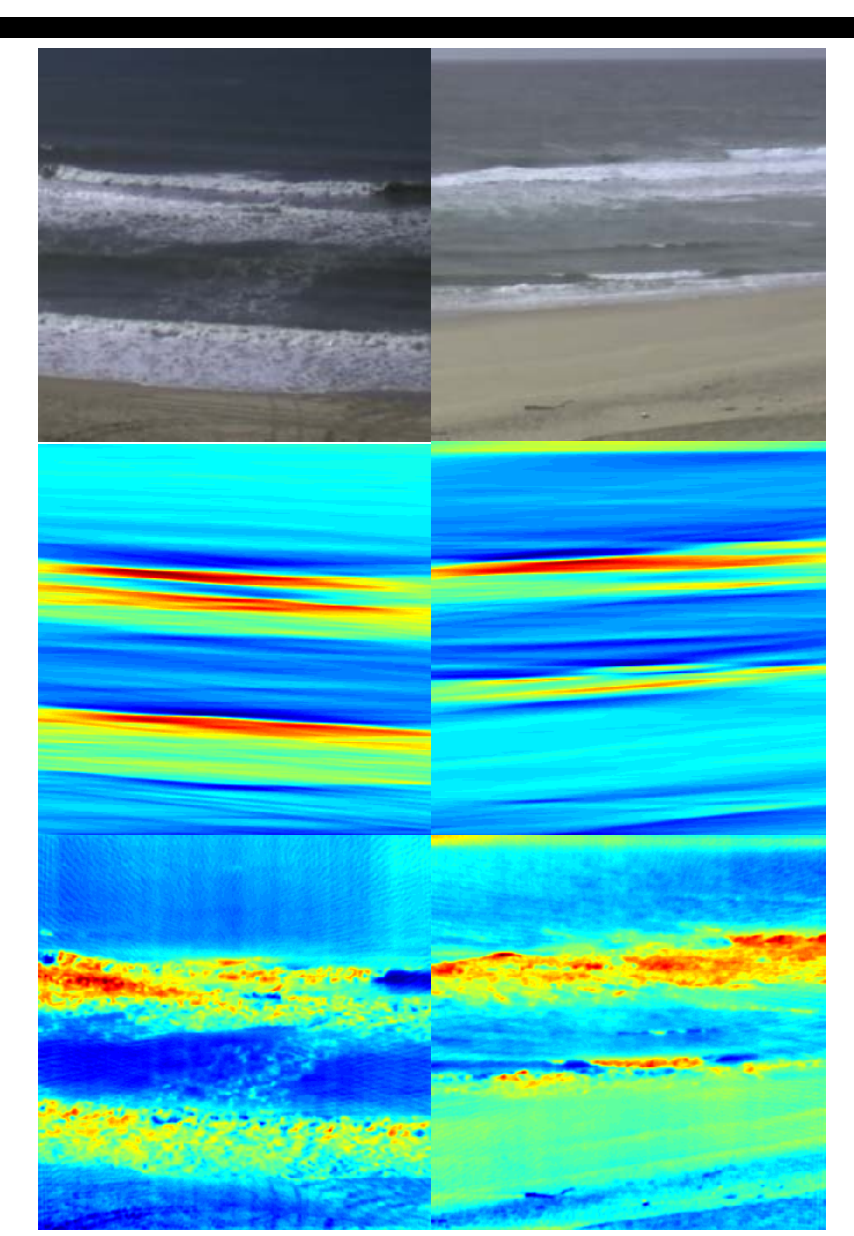

Figure 13. From up to down, original images, filtered to obtain the waves, filtered to obtain the foam.

Holman, R.A., Sallenger, A.H. Jr., Lippman, T.C., and Haines, J.W., 1993. The application of video image processing to the study of nearshore processes. Oceanography, 6(3):78-85

Laibi, R., Anthony, E., Almar, R., Castelle, B., Senechal, N., Kestenare, E., 2014. Longshore drift cell development on the human-impacted Bight of Benin sand barrier coast, West Africa. In Proceedings 13th International Coastal Symposium (Durban, South Africa), Journal of Coastal Research, Special Issue No. 66, ISSN 0749-0208

Larnier, S., Almar, R., Cienfuegos, R., and Lejay, A., 2013, Détection de courants marins côtiers à partir de sequences video. (submitted) 
Lippmann, T.C. and Holman, R.A., 1990. The spatial and temporal variability of sand bar morphology. J. Geophys. Research: Oceans, 95(C7):11575-11590.

Lippmann, T.C. and Holman, R.A., 1991. Phase speed and angle of breaking waves measured with video techniques. In N.C. Kraus, K.J. Gingerich, and D.L. Kriebel, editors, Coastal Sediments, 542-556.

Mallat, S., 2009. A wavelet tour of signal processing: The sparse way. Elsevier/Academic Press, Amsterdam, 3 edition. With contributions from Gabriel Peyré.

Muetze, A. and Vining, J.G., 2006. Ocean wave energy conversion - a survey. In 41st IAS Annual Meeting. Conference Record of the 2006 IEEE Industry Applications Conference, vol. 3, 1410-1417.

Plant, N.G. and Holman, R.A., 1997. Intertidal beach profile estimation using video images. Mar. Geol., 140:1-24.

Senechal, N., Abadie, S., Gallagher, E., MacMahan, J., Masselink, G., Michallet, H., et al., 2011. The ECORS-Truc Vert'08 nearshore field experiment: presentation of a three-dimensional morphologic system in a macro-tidal environment during consecutive extreme storm conditions. Ocean Dynamics, 61(12): 2073-2098.

Stockdon, H.F. and Holman, R. A., 2000. Estimation of wave phase speed and nearshore bathymetry from video imagery. J. Geophys. Research: Oceans, 105(C9):22015-22033.

Ramm, A.G. and Katsevich, A.I., 1996. The Radon transform and local tomography. CRC Press, Boca Raton, FL.

Villagran, M., Cienfuegos, R., Catalan, P. and Almar, R., 2013. Morphological response of central Chile sandy beaches to the 8:8 Mw 2010 earthquake and tsunami. In Proceeding of Coastal Dynamics, 2428 June 2013, Arcachon, France, 1823-1834.

(S. Larnier) LAAS-CNRS, Université Paul Sabatier, Toulouse, France. stanislas.larnier@laas.fr

(R. Almar) IRD-LEGOS, Université Paul Sabatier, Toulouse, France. rafael.almar@ird.fr

(R. Cienfuegos) CIGIDEN, Pontificia Universidad Catolica, Santiago, Chile.racienfu@ing.puc.cl

(A. Lejay) Inria-IECL, Université de Lorraine, Nancy, France. antoine.lejay@inria.fr 